\title{
Sudden infant death and cytomegalovirus inclusion disease
}

\author{
S VARIEND,* RG PEARSE, $\dagger$ \\ From the *Department of Histopathology, Sheffield Children's Hospital, and $†$ Neonatal Intensive Care Unit, \\ Jessop Hospital for Women, Sheffield
}

SUMMARY Four infants, apparently thriving and without clinical evidence of disease, died suddenly at ages ranging from 2 to 6 months. Inclusions bearing cells pathognomonic of cytomegalovirus infection were shown microscopically in a small number of extraneural organs. In view of the lack of associated tissue destruction on microscopy and the apparent well being of the infants before death whether the function of these organs had been impaired to any important degree was questionable: such limited disease, consequently, could not have contributed substantially to the cause of death.

The brainstem, on the other hand, consistently showed small numbers of glial nodules. Damage to strategically located neurones associated potentially with the organisation of vital function was a possible basis of sudden death. Alternatively, the small number of glial nodules may have represented a residue of previous more severe brainstem disease, which had possibly started while the baby was in the uterus.

Congenital cytomegalovirus (CMV) infection is common: reported incidences in the United Kingdom range from $0.3 \%$ to $0.4 \% .{ }^{12}$ Few babies, however, develop potentially serious neonatal disease. ${ }^{2}$ The clinical picture in such cases is usually one of jaundice, anaemia, hepatosplenomegaly, pneumonitis, and purpuric rash, with or without central nervous system disease. Among those who survive a late mortality exists, and this can usually be attributed to severe neurological disability. ${ }^{3}$

There are two types of neonatal central nervous system disease associated with CMV infection. ${ }^{4}$ One is a severe necrotising encephalomyelitis, the other a glial nodular encephalitis. The two may coexist or occur independently. Glial nodule encephalitis has also been described in association with CMV disease in adults after renal transplantation and immunosuppressive treatment. ${ }^{56}$

There is increasing evidence to suggest that an appreciable number of infants with occult congenital CMV infection progress subsequently to mild degrees of mental subnormality and sensorineural deafness. ${ }^{7}$ Glial nodules have been implicated in the morphological expression of the subclinical encephalitis that is responsible for such late neurological sequelae. $^{8}$

Accepted for publication 18 December 1985
Sudden infant death in association with CMV disease is generally regarded as rare, ${ }^{9}$ although isolated cases attributable to $\mathrm{CMV}$ associated interstitial pneumonitis have been reported. ${ }^{10-12} \mathrm{~A}$ single report drew an association between sudden infant death and CMV inclusions localised to the parotid. ${ }^{13}$ Two of five infants in that study also had glial nodule encephalitis, although details were not provided, and a causal association with CMV was not concluded. The purpose of this report is firstly to focus on the occurrence of sudden death among seemingly well infants subsequently found to have evidence of limited CMV disease at necropsy. Secondly, we draw attention to the presence of glial nodules in the brainstem as a possible explanation for sudden death among such infants.

\section{Material and methods}

Necropsies were carried out according to a standardised protocol. Limited virological studies were performed on lung and stool but did not include a specific search for CMV. Samples of vitreous humour were analysed biochemically. Tissue samples were obtained from all organs and fixed in formalin for periods ranging from two to three weeks. Brain tissue was sampled for microscopy from the following sites: cerebral hemisphere, midbrain, midpons, medulla oblongata, 
cerebellar hemisphere, and spinal cord.

\section{CASE 1}

He was born to a 21 year old gravida 4 with one normal child. There had been a previous miscarriage at 12 weeks and an unexplained intrauterine death at 38 weeks. This pregnancy was uneventful but ended in an emergency caesarean section for fetal bradycardia. Birth weight was $933 \mathrm{~g}$ at an estimated gestational age of 35 weeks, and assisted ventilation was required for six hours. Jaundice developed during the first 24 hours, and a grade 1 intraventricular haemorrhage, self limiting bradycardia, and a patent ductus arteriosus were further complications. Weight gain was rapid and he was discharged after 48 days. Two months later at the baby clinic progress was considered to be satisfactory. He was found dead the next morning.

\section{CASE 2}

He was delivered at home with weight of $1030 \mathrm{~g}$ at birth to an unmarried primigravida whose pregnancy had been undiagnosed. Gestational age was estimated at 25 weeks. Thirteen days of ventilator support were required for severe idiopathic respiratory distress syndrome. Jaundice developed on the first day, peaking at $225 \mathrm{mmol} / 1(13.2 \mathrm{mg} / \mathrm{dl})$ on day 6 . Further complications included subependymal haemorrhage, pulmonary consolidation, necrotising enterocolitis, neonatal hepatitis, conjunctivitis, and frequent cyanotic spells. Cytomegalovirus titre on day 5 was 64 and a repeat CMV titre on day 41 was 64. CMV IgM was, however, negative, and a specimen of urine failed to grow CMV. Blood transfusions were administered on days $22,38,47$, and 60 .

After discharge he made satisfactory progress. Six weeks before death he was seen by the family doctor for diarrhoea. There were no other problems, and on the day before death there had been no cause for concern. Aged 6 months he was found dead in his cot.

\section{CASE 3}

She was born after caesarean section for intrauterine growth retardation. Apgar scores were 9 and 10, and the gestational age was 37 weeks with a birth weight of $2200 \mathrm{~g}$. Phototherapy was given for jaundice which peaked on day 3. Excellent progress was made subsequently, and at follow up in the baby clinic at 8 weeks her weight gain was satisfactory. A review at 12 weeks showed eczema, and nystaform was prescribed. She became restless and was not sleeping well three days before death. On this day she was seen by the family doctor, who, apart from eczema, could find nothing untoward. Aged $3 \frac{1}{2}$ months she was found dead in her pram.

\section{CASE 4}

She was born after an uneventful pregnancy and full term normal delivery with a birth weight of $2410 \mathrm{~g}$. Mother and baby were discharged from hospital after six days. Subsequent progress was normal and her condition did not cause concern. She was seen by the family doctor six weeks before death for colic and two weeks later for a "sweat" rash. These ailments, however, rapidly resolved and she continued to gain weight. Two weeks before death she weighed $4620 \mathrm{~g}$ (between the 10th and 25th percentile for age). Aged 11 weeks, she was found dead in her cot.

\section{Results}

With the exception of petechiae affecting the thymic capsule and visceral pleurae in cases 2,3 , and 4 naked eye findings were essentially unremarkable in all cases and sudden infant death syndrome (cot death) was tendered as the provisional cause of death before histological examination. On microscopy CMV inclusions in the parotid were shown in all the cases (Fig. 1 ), and cases 1, 2, and 4 also showed focal nuclear inclusions in the kidney. The medulla of one adrenal gland in case 2 also showed a few inclusions and case 3 showed an occasional lymphocytic focus in the liver and kidneys. The inclusions were never widespread and there was no associated tissue necrosis, although moderate chronic inflammation was often present. Particles resembling rotavirus were observed on electron microscopy of the stool in case 3 . Virological and

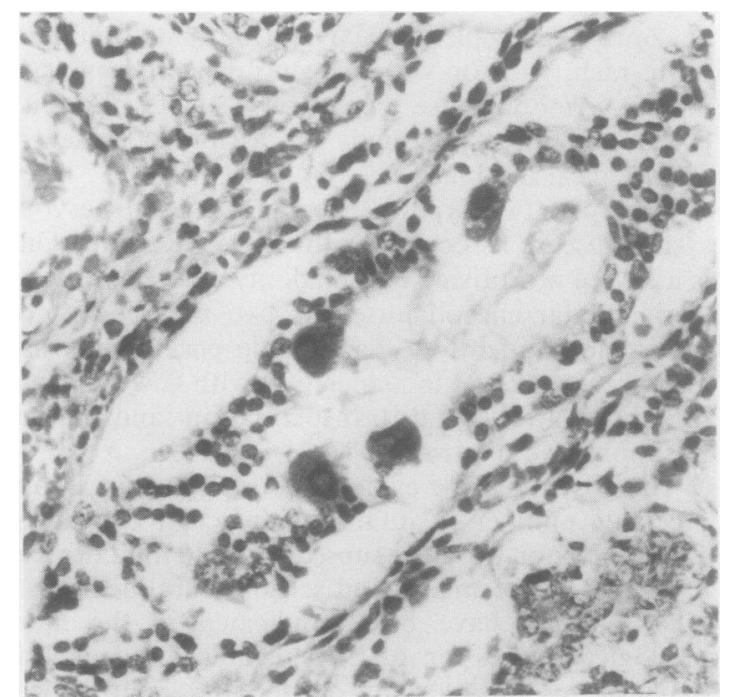

Fig. 1 Inclusions bearing cytomegalic cells are seen within ductal epithelium of parotid (Haematoxylin and eosin.) $\times$ 70. 


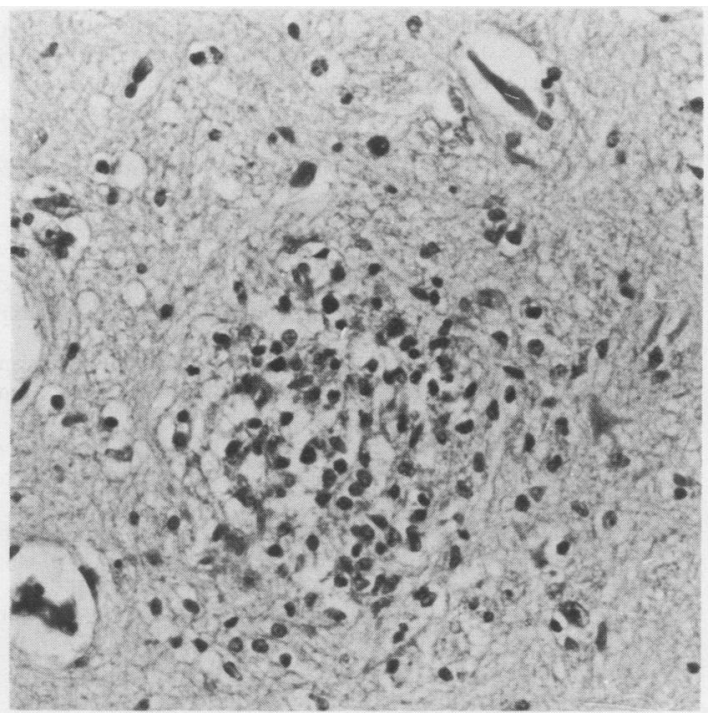

Fig. 2 Glial-nodule in pons (Haematoxylin and eosin.) $\times$ 23.

bacteriological investigation yielded negative results in the other cases.

Occasional glial nodules were seen in the initial brainstem sections of cases 1, 2, and 3 (Fig. 2), but further sectioning was required for their confirmation in case 4. Neurones were occasionally incorporated within the glial nodules or were seen along their immediate perimeters (Fig. 3). Intranuclear inclusions were not observed, and the remainder of the brain was unremarkable on microscopy.

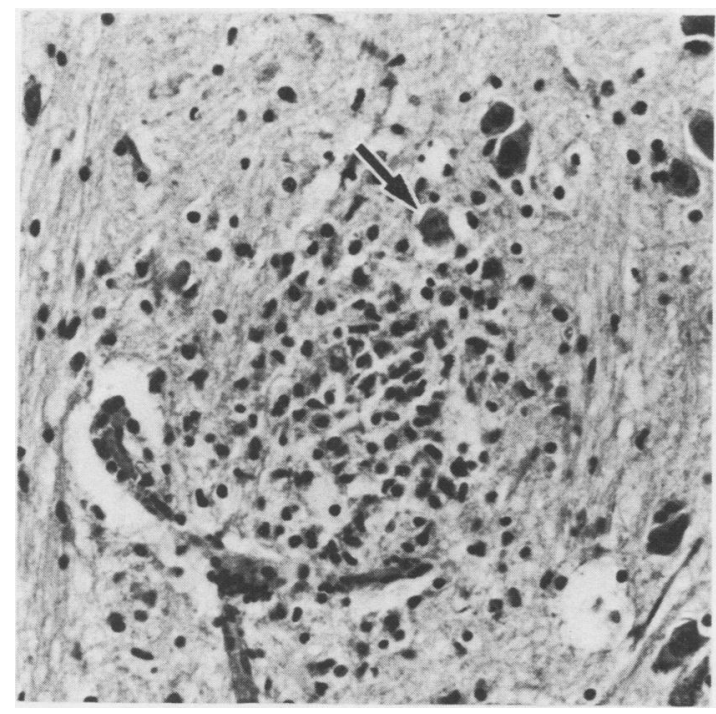

Fig. 3 Glial-nodule in pons incorporating neurone (arrow) (Haematoxylin and eosin.) $\times 70$.
In case $1 \mathrm{CMV}$ disease had not been considered during life, but a sample of serum stored from the day of birth was retrieved and showed positive IgG but negative IgM (enzyme immunoassay). A necropsy sample, however, was negative for IgG and IgM. In case 2 a serum sample subsequently taken from the mother was negative for IgM but positive for CMV IgG to a titre of $1 / 16$ (complement fixation test).

\section{Discussion}

Two of the infants were born preterm, a recognised association with CMV infection. Infection in these cases may, however, be congenital or acquired, and the distinction may be impossible even when serological information is available. ${ }^{14}$ Maternal CMV serology was not available in case 1 . The falling serum IgG in this infant (assayed in retrospect) may have reflected maternal antibody decay, and an apparent failure of endogenous antibody production in the presence of subsequent histologically confirmed CMV disease cannot easily be explained. Many aspects of the neonatal illness presented by case 2 were compatible with CMV infection, and the raised CMV IgG titre detected subsequently in the mother strongly suggested a congenital origin. In the remaining two cases no serological data were available as CMV had not been suspected in life.

Two of the infants (cases 1 and 4) were checked at a baby clinic, in one case one day before, and in the other two weeks preceding death. For the two other infants (cases 2 and 3) medical advice was sought for diarrhoea six weeks before death in one case, and for "restlessness" three days before death in the other. Thus all infants at the time seemed to be making satisfactory progress, or were prescribed for what seemed to be only minor or non-specific ailments.

Necropsy histology showed that the parotid and kidney were the organs which showed inclusion bearing cytomegalic cells most often. One of the cases also showed a few inclusions in one adrenal medulla. The importance of focal lymphocytic infiltration in the kidney and liver in the absence of CMV inclusions in case 3 is not known, although resolving disease is a possibility. None of the organs seemed to be adversely affected and none showed histological evidence of tissue necrosis. The proof of inclusion bearing cells in the organs of infants who did not manifest important clinical illness raises doubts about whether the function of these organs had been adversely compromised. Moreover, disease in these organs seems an unlikely basis for sudden death.

Sparse glial nodules in the brainstem were a consistent histological finding. Their occurrence in newborn infants has also been documented but usually against a background of extensive CMV disease in extra- 
neural tissues. ${ }^{1516}$ Although viral inclusions are occasionally shown within the glial nodules in adults and infants, ${ }^{516}$ their presence coincides almost invariably with evidence of CMV disease in other organs, suggesting a causal connection with CMV. Glial nodules of similar structure are rarely seen in patients dying of uraemia ${ }^{17}$; in such cases, however, they are usually located within white matter rather than grey matter, and in our cases uraemia was ruled out on the basis of necropsy vitreous chemistry. Only two of the infants reported here (cases 3 and 4 ) received routine immunisation, and there was no evidence of concomitant viral infection apart from case 3 who had probable enteral rotavirus.

Disease in the brainstem is a more rational basis for sudden death, and, indeed, this anatomical site has often been implicated as harbouring pathology that might explain the mechanism of the sudden infant death syndrome. ${ }^{18}{ }^{19}$ Glial nodules in the hindbrain in the present series were very sparse, presumably as only a few microscopic sections were examined. This report, however, describes their presence, but quantitation and precise localisation must await more detailed study.

The brainstem has one of the heaviest concentrations of neurones, many of which are placed strategically to regulate and coordinate vital functions including respiratory and cardiac control. ${ }^{2021}$ Thus it is conceivable that disease in only a few selected neurones in this highly complex network may be crucial. Another possibility is that the few glial nodules identified were a residue of a previous more severe encephalitic process, which had possibly begun long before the child was born.

We thank Dr J Bridson for providing clinical details pertaining to case 2 .

\section{References}

${ }^{1}$ Peckham CS, Coleman JC, Hurley R, Chin KS, Henderson K Preece PM. Cytomegalovirus infection in pregnancy: preliminary findings from a prospective study. Lancet 1983;ii:1352-5.
2 MacDonald H, Tobin JO'H. Congenital cytomegalovirus infection: a collaborative study on epidemiological, clinical and laboratory findings. Dev Med Child Neurol 1978;20:471-82.

${ }^{3}$ Berenberg W, Nankervis G. Long term follow-up of cytomegalic inclusion disease of infancy. Pediatrics 1970;46:403-9.

${ }^{4}$ Friede RL. Developmental neuropathology. New York: SpringerVerlag, 1975.

${ }^{5}$ Schneck SA. Neuropathological features of human organ transplantation. 1. Probable cytomegalovirus infection. $\mathrm{J} \mathrm{Neu}$ ropathol Exp Neurol 1965;24:415-29.

${ }^{6}$ Dorfman LJ. Cytomegalovirus encephalitis in adults. Neurology 1973;23:136-44.

${ }^{7}$ Weller TH. The cytomegalovirus: ubiquitous agents with preterm clinical manifestations (second of two parts). New Eng $J$ Med 1971;285:267-74.

${ }^{8}$ Schopter K, Lauber E, Krech U. Congenital cytomegalovirus infection in newborn infants of mothers infected before pregnancy. Arch Dis Child 1978;53:536-9.

${ }^{9}$ Valdes-Dapena M. Sudden unexplained infant death, 1970 through 1975. An evolution in understanding. Pathol Annu 1977:117-45.

${ }^{10}$ Raven C. Sudden infant death syndrome. JAMA 1976;235:249.

${ }^{11}$ Smith SD, Cho CT. Cytomegalovirus pneumonia in sudden infant death syndrome. JAMA 1975;233:861.

${ }^{12}$ Ray CG, Hebestreit NM. Studies of the sudden infant death syndrome in King County, Washington: II. Attempts to demonstrate evidence of viraemia. Pediatrics 1971;48:79-82.

${ }^{13}$ Müller G, Hesse R. Cytomegalie und plötzlicher Kindstod. Frankfurter Zeitschrift für Pathologie 1960;70:409-16.

${ }^{14}$ Ahlfors K, Ivarsson SA, Johnsson T. Serological differentiation of congenital and acquired cytomegalovirus infections detected in infancy. Acta Paediatr Scand 1979;68:507-12.

${ }^{15}$ Beecroft DMO. Prenatal cytomegalovirus infection: epidemiology, pathology and pathogenesis. Perspect Pediatr Pathol 1981;6:203-41.

${ }^{16}$ Vortel V, Plachy V. Glial-nodule encephalitis associated with generalised cytomegalic inclusion body disease. Am J Clin Pathol 1968;49:319-24.

${ }^{17}$ Olsen S. The brain in uraemia. Acta Psychiatrica et Neurologica Scandinavica 1961;36 (suppl 156):77-80.

${ }^{18}$ Takashima S, Armstrong D, Becker L, Bryan C. Cerebral hypoperfusion in the sudden infant death syndrome? Brainstem gliosis and vasculature. Ann Neurol 1978;4:257-62.

${ }^{19}$ Summers CG, Parker JC. The brainstem in sudden infant death syndrome. A post mortem study. Am J Forensic Med Pathol 1981;2:121-7.

${ }^{20}$ Berger AJ, Mitchell RA, Severinghaus JW. Regulation of respiration. New Engl J Med 1977;297:138-43.

${ }^{21}$ Bannister R. Autonomic failure. Proceedings of Royal College of Physicians of Edinburgh 1985;15:71-90.

Requests for reprints to: Dr S Variend, Department of Histopathology, Children's Hospital, Western Bank, Sheffield S10 2TH, England. 